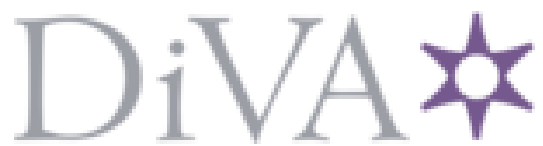

http://www.diva-portal.org

This is the published version of a paper published in ACS Nano.

Citation for the original published paper (version of record):

Garemark, J., Yang, X., Sheng, X., Ocean, C., Sun, L. et al. (2020)

Top-Down Approach Making Anisotropic Cellulose Aerogels as Universal Substrates for Multifunctionalization

ACS Nano

https://doi.org/10.1021/acsnano.0c01888

Access to the published version may require subscription.

N.B. When citing this work, cite the original published paper.

Permanent link to this version:

http://urn.kb.se/resolve?urn=urn:nbn:se:kth:diva-280905 


\title{
Top-Down Approach Making Anisotropic Cellulose Aerogels as Universal Substrates for Multifunctionalization
}

\author{
Jonas Garemark, Xuan Yang, Xia Sheng, Ocean Cheung, Licheng Sun, Lars A. Berglund, \\ and Yuanyuan $\mathrm{Li}^{*}$
}

Cite This: ACS Nano 2020, 14, 7111-7120

ABSTRACT: Highly porous, strong aerogels with anisotropic structural properties are of great interest for multifunctional materials for applications including insulators in buildings, filters for oil cleanup, electrical storage devices, etc. Contemporary aerogels are mostly extracted from fossil resources and synthesized from bottom-up techniques, often requiring additional strategies to obtain high anisotropy. In this work, a universal approach to prepare porous, strong, anisotropic aerogels is presented through exploiting the natural hierarchical and anisotropic structure of wood. The preparation comprises nanoscale removal of lignin, followed by dissolution-regener-

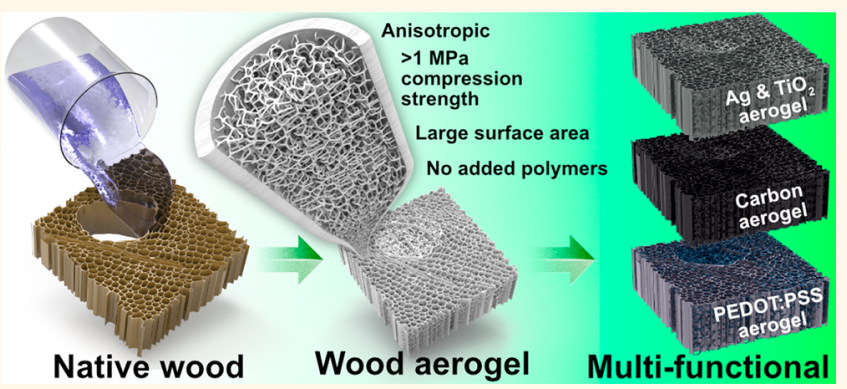
ation of nanofibers, leading to enhanced cell wall porosity with nanofibrillated networks occupying the pore space in the cellular wood structure. The aerogels retain structural anisotropy of natural wood, exhibit specific surface areas up to $247 \mathrm{~m}^{2} /$ $\mathrm{g}$, and show high compression strength at $\mathbf{9 5 \%}$ porosity. This is a record specific area value for wood aerogels/foams and even higher than most cellulose-based aerogels for its assigned strength. The aerogel can serve as a platform for multifunctional composites including scaffolds for catalysis, gas separation, or liquid purification due to its porous matrix or as binder-free electrodes in electronics. To demonstrate the multifunctionality, the aerogels are successfully decorated with metal nanoparticles $(\mathrm{Ag})$ and metal oxide nanoparticles $\left(\mathrm{TiO}_{2}\right)$ by in situ synthesis, coated by the conductive polymer (PEDOT:PSS), and carbonized to yield conductive aerogels. This approach is found to be a universal way to prepare highly porous anisotropic aerogels.

KEYWORDS: aerogel, anisotropy, top-down, wood nanotechnology, biocomposite

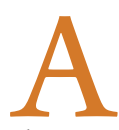

erogels are porous solids often prepared from a gel form substrate where a solvent is exchanged for air or gas. ${ }^{1}$ The aerogels exhibit high surface area and low density, rendering them suitable in a broad range of materials applications, ranging from insulators in buildings to supercapacitors in electrical devices. ${ }^{2,3}$ A wide variety of aerogels are available, among which inorganic silica aerogels are most studied. However, the impaired strength properties limit their use. Synthetic polymers can overcome fragility problems, but the strength is limited and they are often derived from fossil resources. Aerogels based on natural polymers are of increasing interest due to potential eco-friendly characteristics. Reported biobased aerogels include bacterial cellulose, ${ }^{4}$ starch, ${ }^{5}$ alginate, ${ }^{6}$ lignocellulose, and chitosan-based aerogels.

Cellulose nanofiber (CNF) aerogels are interesting due to high strength-to-density and large surface area-to-weight ratios. $^{8}$ The low thermal conductivity renders them suitable for insulating purposes. ${ }^{9,10}$ Low density is an advantage, and the highly tailorable pores show promise for drug delivery, ${ }^{11}$ filters, and adsorbent applications. ${ }^{12,13}$ Through tailoring of the conductivity, the aerogels have also been used as components in electronic devices. ${ }^{14}$

The nanocellulose fibrils in the aerogels are generally attained from either mechanical disintegration or acid hydrolysis, in which the mechanical approach often requires a preceding treatment such as TEMPO-mediated oxidation ${ }^{15}$ or enzymatic pretreatment ${ }^{16}$ to decrease the energy demand during mechanical defibrillation. ${ }^{17} \mathrm{CNF}$ aerogels are based on

Received: March 4, 2020

Accepted: May 15, 2020

Published: May 15, 2020 
the bottom-up approach, where nanocellulose is extracted from sources and prepared by reconstructing of the building blocks to form aerogels. This approach is time-consuming and energy intensive and usually results in aerogels with isotropic structural properties. An anisotropic structure is beneficial where directional conduction is needed, such as electrodes for batteries and substrates for solar steam evaporation. ${ }^{18,19}$ However, assembly of anisotropic materials is challenging. For nanocellulose aerogels, a common method is directional freeze-casting, in which ice crystallites are formed by inducing a temperature gradient during freezing. Even though the method is useful, the addition of auxiliary processing steps results in time demanding, costly fabrication with substantial energy needs. ${ }^{8,20,21}$

An alternative approach is a top-down synthesis of aerogels. Instead of reassembly of nanosized building blocks, this method can take advantage of the hierarchical structure of wood. Wood consists of anisotropic and highly elongated cells (20-30 $\mu \mathrm{m}$ in diameter, $1-3 \mathrm{~mm}$ in length), organized in a parallel manner. This results in orthotropic mechanical properties, but the cells can also transport water and nutrients for biosynthesis. ${ }^{22}$ The wood cell wall is a nanostructured composite, comprised of layers of cellulose nanofibril reinforcement embedded in a hydrated matrix of molecularly mixed hemicelluloses and lignin. In the thickest S2 layer the cellulose fibrils are strongly oriented at a comparably small angle with respect to the axial direction of the wood cell. The structural organization of the cells and the directional alignment result in excellent mechanical properties. Functionalization of the structure at the molecular or nanoscale could result in multifunctional nanomaterials of potential for largescale applications. ${ }^{23,24}$ One limitation is the low specific surface area of wood structure. Preparation of wood structured aerogels is one solution, where the structural anisotropy is retained. Thus far, one type of wood aerogel has been reported, where the cell wall was delignified and part of the hemicellulose was removed. ${ }^{9,25,26}$ However, none of these materials previously studied have a specific surface area comparable with nanocellulose-based aerogels.

In this paper, a highly porous anisotropic wood aerogel is prepared by a top-down synthesis method based on nanostructural wood cell wall manipulation. The preparation comprises delignification followed by partial dissolution/ regeneration of the cell wall using dimethylacetamide/lithium chloride (DMAc/LiCl). The cosolvent partially dissolves the cell wall and regenerates nanofibrils. As a result, a porous cell wall is obtained with a nanofibrous network in the central lumen pore space of wood cells. Figure 1 illustrates the wood aerogel preparation procedure. This approach preserves the structural anisotropy of wood and introduces exceptional specific surface areas. The combination of formed nanofibrils in the cell lumen and retention of highly aligned cellulose of the cell walls leads to a rare combination of large surface area with good mechanical strength, not commonly seen in aerogels. The aerogel is further modified by in situ synthesis of $\mathrm{Ag}$ nanoparticles and $\mathrm{TiO}_{2}$ nanoparticles that effectively deposited on both the cell walls and the formed nanofibrils of the cell lumen. The conductive polymer (PEDOT:PSS) (poly(3,4-ethylenedioxythiophene) polystyrenesulfonate) is seamlessly coated onto the aerogel, and carbonization of the aerogel is also performed to yield conductive carbon aerogels with an extensive surface area. This highly adaptable aerogel

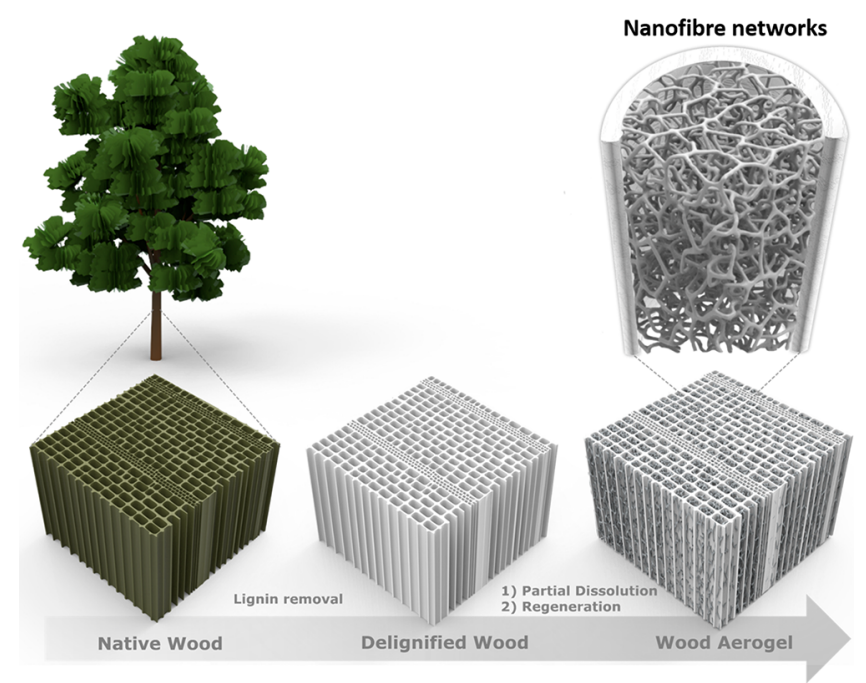

Figure 1. Schematic illustration of the wood aerogel preparation procedure.

shows promise as an eco-friendly alternative for multifunctional scaffolds in several application areas.

\section{RESULTS AND DISCUSSION}

Balsa wood derived aerogels with retained hierarchical structure were prepared first by delignification to increase porosity and chemical accessibility. After delignification, the wood was treated with an $8 \mathrm{wt} \%$ solution of $\mathrm{DMAc} / \mathrm{LiCl}$ for $24 \mathrm{~h}$, which partially dissolved the wood cell wall. The samples were subjected to solvent exchange to precipitate, followed by freeze-drying or critical point drying (CPD) to form aerogels. This is a facile preparation of biobased anisotropic aerogels; however, from a perspective of large-scale production, the drying methods could potentially be an obstacle. The preparation is exemplified in Figure 2, depicting the change in chemical composition, material properties, and BrunauerEmmet-Teller (BET) specific surface area (SSA). Images of typical dimensional changes of the specimens are shown in Figure S1a-c, and data of dimensional change, weight change, and density are seen in Table S1. The average material yield after delignification and freeze-drying was 76 wt \%, whereas the wood aerogels obtained a yield of $60 \mathrm{wt} \%$. This means removal of lignin represented the larger material loss, and the dissolution/regeneration process the lesser.

The delignification procedure was performed with $\mathrm{NaClO}_{2}$ in an acetate buffer solution of $\mathrm{pH}$ 4.6. Delignification takes place by radical action of $\mathrm{ClO}_{2}$, where aromatic rings are oxidized, resulting in ring-opening reactions that effectively decomposes the lignin. Nearly $90 \%$ of lignin was removed during the procedure (Figure 2). After the procedure, the lightabsorbing chromophoric groups, mainly from lignin, were removed, resulting in a white texture (Figure $3 a$ and $b$ ). As lignin was removed, the cell wall layers became partially delaminated and voids were generated in the previously ligninrich middle lamella (Figure $3 \mathrm{~d}$ and e). In addition, nanoscale pores are generated in the cell wall after delignification, as reported by $\mathrm{Fu}$ et $a .^{27}$ The extensive loss of lignin and increased cell wall porosity resulted in a more accessible cell wall for chemical agents. Data recorded by the $\mathrm{N}_{2}$ sorption method and the calculated BET surface area support the observation of increased cell wall porosity (Figure 4a). The 


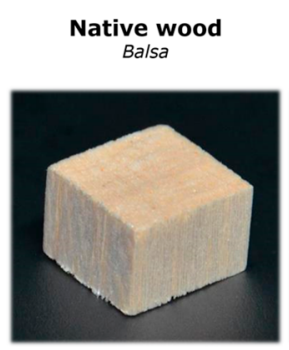

Lignin: $22 \%$ Cellulose: $56 \%$ Hemicellulose: $22 \%$ Density: $129 \pm 2 \mathrm{~kg} / \mathrm{m}^{3}$ Porosity: $92 \pm 2 \%$ SSA (FD): $2 \mathrm{~m}^{2} / \mathrm{g}$
Delignification $\mathrm{NaClO}_{2}$ - Acetate buffer $18 \mathrm{~h}$

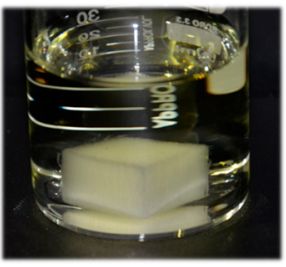

Lignin: $2 \%$

Cellulose: $75 \%$

Hemicellulose: $23 \%$

Density: $90 \pm 12 \mathrm{~kg} / \mathrm{m}^{3}$ SSA (FD): $9 \mathrm{~m}^{2} / \mathrm{g}$
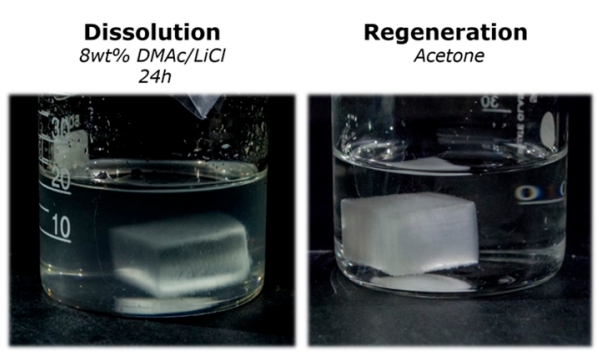

Wood aeroge

Freeze-dried $-83^{\circ} \mathrm{C}$

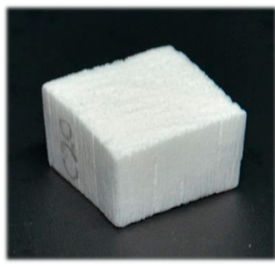

Lignin: 2\%

Cellulose: $73 \%$

Hemicellulose: $25 \%$

Density: $79 \pm 8 \mathrm{~kg} / \mathrm{m}^{3}$

Density: $79 \pm 8 \mathrm{~kg} / \mathrm{m}$

SSA (FD): $131 \pm 22 \mathrm{~m}^{2} / \mathrm{g}$

SSA (FD): $131 \pm 22 \mathrm{~m}^{2} / \mathrm{g}$
SSA(CPD): $181 \pm 47 \mathrm{~m}^{2} / \mathrm{g}$

Figure 2. Schematic of the synthesis procedure and characterization of the specimen, including data from sugar analysis, Klason lignin analysis, BET specific surface area measurements, and density measurements.
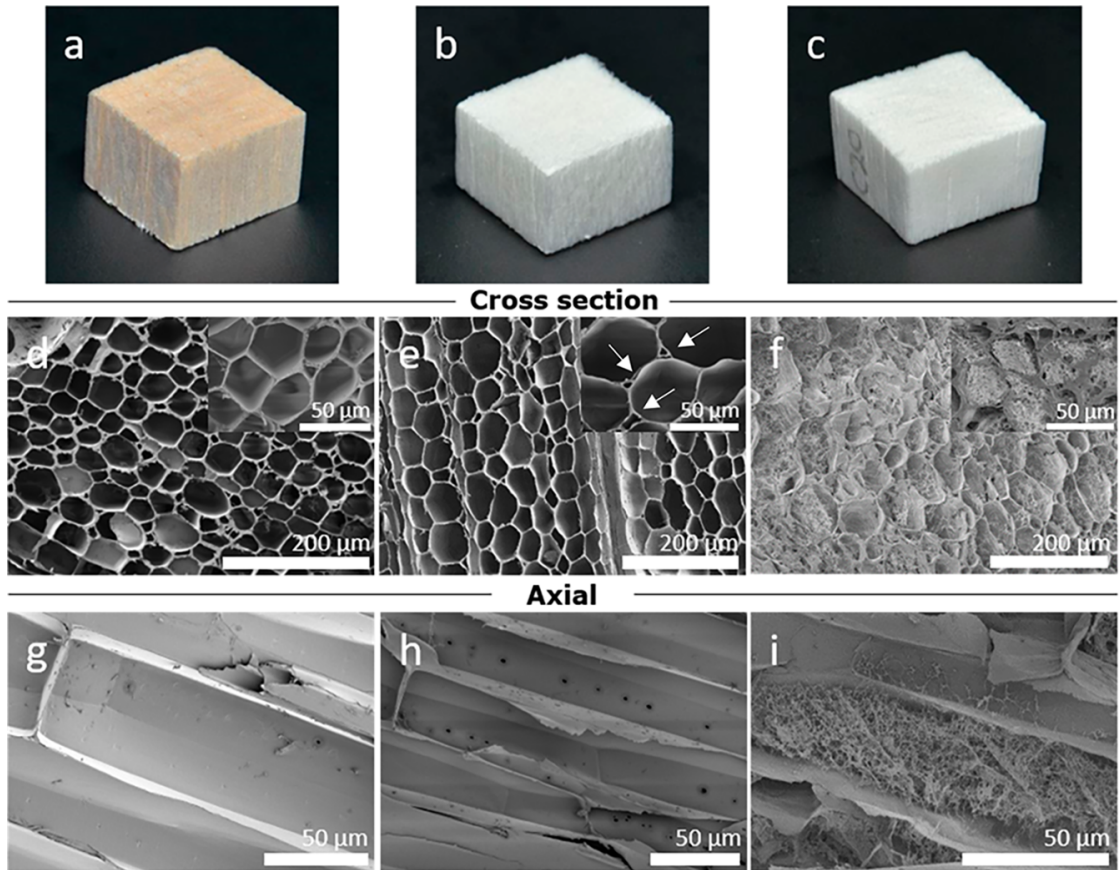

Figure 3. DMAc/LiCl-treated wood at different stages. (a, b, and c) Native wood, delignified wood, and DMAc/LiCl-treated wood aerogel, respectively. ( $\mathrm{d}$ and e) Low-magnification SEM images of native and delignified wood from a cross-section, respectively. Inset images in (d) and (e) display the cell wall structures, while (e) shows the partial delamination of the cell wall pointed by the arrows. (f) Generation of nanofiber networks inside the lumen structure of the balsa wood after delignification and DMAc/LiCl treatment. Inset image exhibits the filling of the lumen with a nanofiber network. ( $g$ and $h$ ) Empty cells along the fiber direction for wood and delignified wood and (i) lumen of the regenerated wood aerogel with a nanofiber network created as a consequence of the DMAc/LiCl treatment.

BET surface area of the wood after delignification and freezedrying (FD) was $9 \mathrm{~m}^{2} / \mathrm{g}$ compared with native wood, exhibiting $2 \mathrm{~m}^{2} / \mathrm{g}$. Note that these values are still very low compared with typical nanocellulose aerogels.

Following delignification, $\mathrm{DMAc} / \mathrm{LiCl}$ treatment was introduced to partially dissolve the wood cell wall. After regeneration of the dissolved cell wall in acetone and drying, a wood aerogel was obtained. The final aerogel shows similar macroscopic appearance as delignified wood (Figure 3c) yet with vastly different nanostructure. From the SEM images of the wood aerogel cross-section, the lumen space of the fibers is filled by a nanofibril network (Figure $3 \mathrm{f}$ ). $\mathrm{DMAc} / \mathrm{LiCl}$ is reported with the ability to extract cell wall components, mainly by dissolving cellulose. ${ }^{28}$ The celluloses then diffuse to the solution localized in the lumen. During this extraction process, the intermolecular interactions in native cellulose are disrupted. ${ }^{28-30}$ When an antisolvent (acetone in this study) is added, intermolecular hydrogen bonds are re-formed and the dissolved cellulose chains coagulate to form nanofibril structures in situ in the lumen. In the regeneration bath, the following reasons limit the diffusion of formed nanofibril network out of the wood: (1) the small pores of the cell wall, (2) the interaction of the nanofibrils and the cell wall, and (3) the shrinkage of the wood structure during the solvent exchange. During the dissolution process, roughly $41 \%$ of the crystalline cellulose was dissolved. Wherein the regenerated cellulose inside the wood accounted for approximately $34 \%$ of the dissolved cellulose, the remaining portion was lost to the regeneration bath. Retention of nanofibril networks of the lumen space after drying is attributed to the high concentration of fibrils and the rapid freezing rate. ${ }^{31}$ The dense presence of fibrils has been reported to hinder growth of ice crystals, 

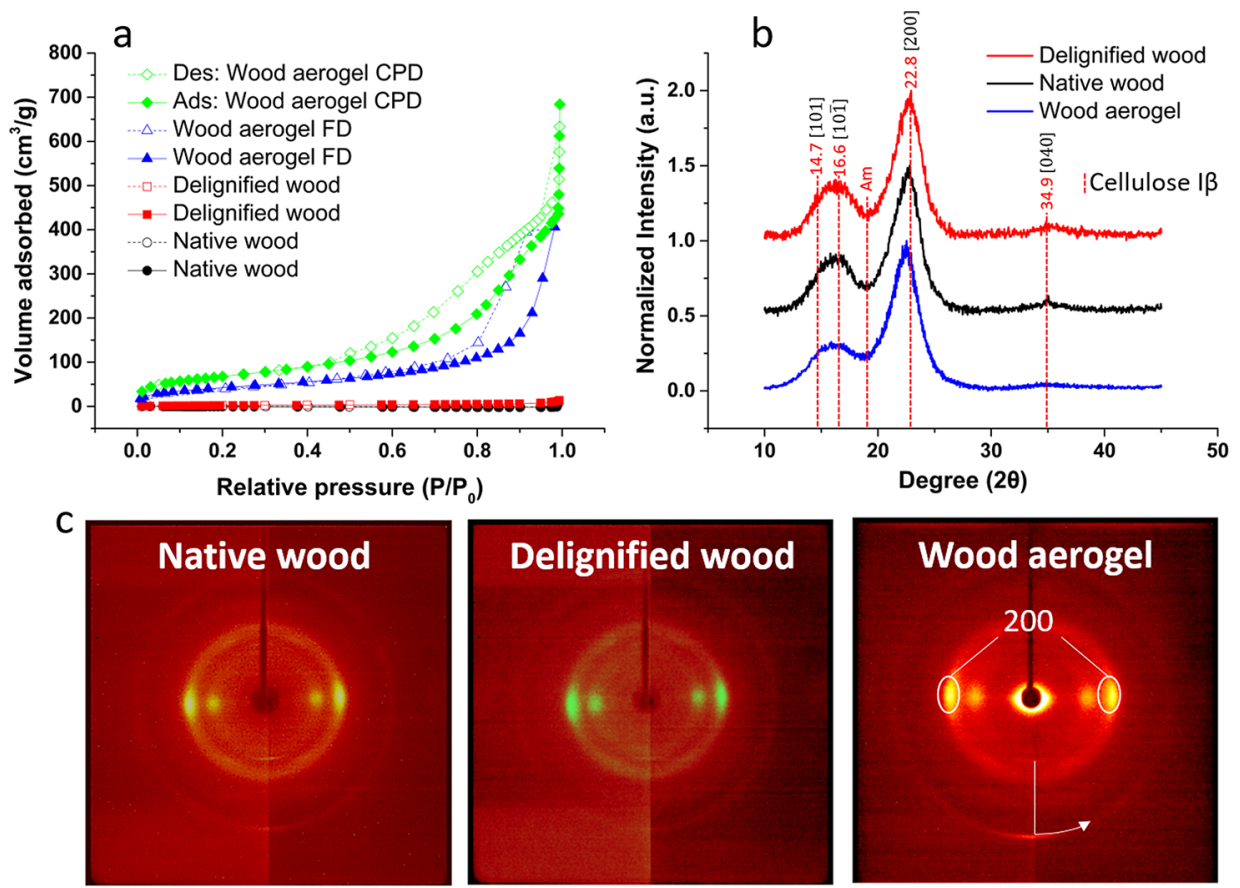

Figure 4. (a) Nitrogen adsorption and desorption measurements of native wood, delignified wood, and wood aerogel. Solid lines display adsorption, whereas dashed lines symbolizes desorption. (b) XRD spectra of native wood, delignified wood, and wood aerogel. (c) Wideangle X-ray diffraction images showing the azimuthal intensity profiles of native wood, delignified wood, and the wood aerogel.

preserving separation of fibrils, observed by Jin et al. ${ }^{31} \mathrm{~A}$ faster freezing rate was also observed to retain separation of the fibrils in nanocellulose aerogels, again through prevention of ice crystal growth.

Figures $3 g-i$ show the plane perpendicular to the fiber direction for native wood (Figure $3 \mathrm{~g}$ ), delignified wood (Figure $3 \mathrm{~h}$ ), and the regenerated wood aerogel (Figure 3i). The regenerated nanofibril network is present in the lumen space throughout the aerogel (Figure 3i), but is absent in the other materials. The regenerated nanofibers showed approximate diameters ranging from 10 to $20 \mathrm{~nm}$ (Figure S2). The nanofiber-filled lumen structure suggests high specific surface area. $\mathrm{N}_{2}$ sorption data showed that the BET surface area reached up to $159 \mathrm{~m}^{2} / \mathrm{g}$ for wood aerogels after $\mathrm{FD}$, seen in Figure 4a. In addition, a higher value of $247 \mathrm{~m}^{2} / \mathrm{g}$ was obtained after CPD. From the results above, a hierarchically structured anisotropic aerogel with very high BET surface area is achieved. The BET surface area of wood after both FD and CPD had higher values than any other documented top-down prepared wood aerogel.

To investigate the partial dissolution mechanism, powder $\mathrm{X}$ ray diffraction (XRD) was performed, displayed in Figure $4 \mathrm{~b}$. Native wood and delignified wood show cellulose I structures with crystallinity indices of 0.73 and 0.83 , respectively. According to the literature, cellulose regeneration from $\mathrm{DMAc} / \mathrm{LiCl}$ dissolution is often in a nonordered manner, consisting of both amorphous and paracrystalline cellulose. ${ }^{32}$ By analyzing the intensity changes of crystalline native cellulose I $\left(14.7^{\circ}, 16.6^{\circ}, 22.8^{\circ}\right.$, and $\left.34.9^{\circ}\right)$ and amorphous cellulose $\left(21.5^{\circ}\right)$, an indication of the dissolution/regeneration mechanism can be acquired. ${ }^{32}$ The regenerated wood aerogel displays lower intensities for cellulose I peaks and a broader amorphous peak, based on a peak deconvolution method. The partially retained peaks for cellulose I confirm its presence in the cell wall. In Figure 4b, the [200] peak for the wood aerogel has a slight shift toward lower angles. The occurrence is not fully known, but it could result from the increase of amorphous cellulose, in close proximity to the crystalline cellulose. Kentaru Abe and Hiroyuko Yamamoto postulated that the swelling matrix of wood interacts mechanically with microfibrils of the cell wall, giving rise to a peak shift upon drying. ${ }^{33}$

Part of the cell wall is apparently not affected by the solvent during the $\mathrm{DMAc} / \mathrm{LiCl}$ treatment. With the peak deconvolution method, the crystallinity index (CI) was calculated to be $73 \%, 83 \%$, and $63 \%$ for native wood, delignified wood, and the wood aerogel, respectively (Table 1 ). The decreased CI of the wood aerogel is a consequence of dissolution and regeneration of cellulose. The broader amorphous peak indicates the formation of regenerated cellulose.

Table 1. Degree of Orientation and Crystallinity Index of Native Wood, Delignified Wood, and Wood Aerogel

\begin{tabular}{lccc} 
& $\begin{array}{c}\text { degree of orientation } \\
{[-]}\end{array}$ & $\begin{array}{c}\text { CI peak height } \\
{[\%]}\end{array}$ & $\begin{array}{c}\text { CI deconvolution } \\
{[\%]}\end{array}$ \\
$\begin{array}{lccc}\text { native wood } \\
\begin{array}{c}\text { delignified } \\
\text { wood }\end{array}\end{array}$ & $0.893 \pm 0.004$ & $81 \pm 1.2$ & $73 \pm 0.9$ \\
$\begin{array}{c}\text { wood aerogel } \\
\text { wood }\end{array}$ & $0.862 \pm 0.025$ & $85 \pm 0.4$ & $83 \pm 2.0$ \\
\hline
\end{tabular}

Despite the chemical treatment, the aerogel still shows preserved macroscopic wood structure. Figure $3 \mathrm{f}$ and i show the main wood cell wall structure preserved, leading to anisotropic properties of the resulting aerogel. The orientation of crystalline cellulose I can provide further information about the orientation of microfibrils of the cell wall. Hence, information about the anisotropy of the material can be obtained. The orientation was extracted through azimuthal integration of the diffraction images obtained from 2D wideangle X-ray scattering (WAXS), seen in Figure 4c. The degree of orientation and CI are summarized in Table 1. The degree 
of orientation of cellulose microfibrils in native wood, delignified wood, and the wood aerogel was $0.89,0.86$, and 0.84 , respectively. For the aerogel, the degree of orientation is significantly higher than for CNF or CNC-based aerogels or foams prepared by freeze-casting. ${ }^{10,20}$ Moreover, according to Kriechbaum et al., ${ }^{10}$ a specific energy consumption of $>3 \mathrm{kWh} /$ $\mathrm{kg}$ was necessary to reach a degree of orientation of 0.82 . In contrast, no mechanical shear is necessary in this work.

The mechanical properties of the native wood, delignified wood, and wood aerogel were characterized by compressive testing in the longitudinal direction. The mechanical behavior is summarized in Table 2 and Figure 5a. Notably, for native

Table 2. Young's Modulus and Yield Strength for Native Wood, Delignified Wood, and Wood Aerogel

\begin{tabular}{lccc} 
& $\begin{array}{c}\text { density } \\
{\left[\mathrm{kg} / \mathrm{m}^{3}\right]}\end{array}$ & $\begin{array}{c}\text { Young's modulus } \\
{[\mathrm{MPa}]}\end{array}$ & $\begin{array}{c}\text { yield strength } \\
{[\mathrm{MPa}]}\end{array}$ \\
$\begin{array}{lccc}\text { native wood } \\
\begin{array}{c}\text { delignified } \\
\text { wood }\end{array}\end{array}$ & $129 \pm 2$ & $295 \pm 24$ & $12.9 \pm 0.9$ \\
wood aerogel & $90 \pm 12$ & $82 \pm 32$ & $3.9 \pm 1.5$ \\
\hline
\end{tabular}

wood, a prominent linear region is shown between 0 and $4 \%$ strain. A clear distinction is apparent for delignified wood, where an initial region probably represents buckling of the edges of the specimen at low strain, followed by the linear region at $2.5-5 \%$ strain. The wood aerogel displays a protracted linear region encompassing $0-6 \%$ of strain before reaching the plateau region, where the cellular structure is collapsing, possibly by cell wall buckling or folding. The Young's modulus of each specimen was 295,82 , and $25 \mathrm{MPa}$ for native wood, delignified wood, and the wood aerogel, respectively. The Young's modulus (compression) of native wood is similar to data reported earlier. ${ }^{27}$ The value is low compared with data for higher density wood, since the volume fraction of wood tissue is only $9 \%$. The structural collapse of native wood occurred at $12.9 \mathrm{MPa}$, in agreement with previous observations. ${ }^{34}$ The highly oriented microfibrils and anisotropy provided by the parallel honeycomb-like cells of native wood and the preserved lignin cell wall adhesive result in a strength significantly higher than for treated wood. Delignified wood attains a yield strength of $3.9 \mathrm{MPa}$, whereas the wood aerogel achieves a yield strength of $1.2 \mathrm{MPa}$. Compared to native wood, the lower strength of delignified wood is due to lignin removal. Furthermore, the delignification results in partial delamination of the cell wall (Figure $3 \mathrm{e}$ ). For the wood aerogel, the $\mathrm{DMAc} / \mathrm{LiCl}$ treatment leads to higher cell wall porosity and lower degree of crystallinity, so that yield strength
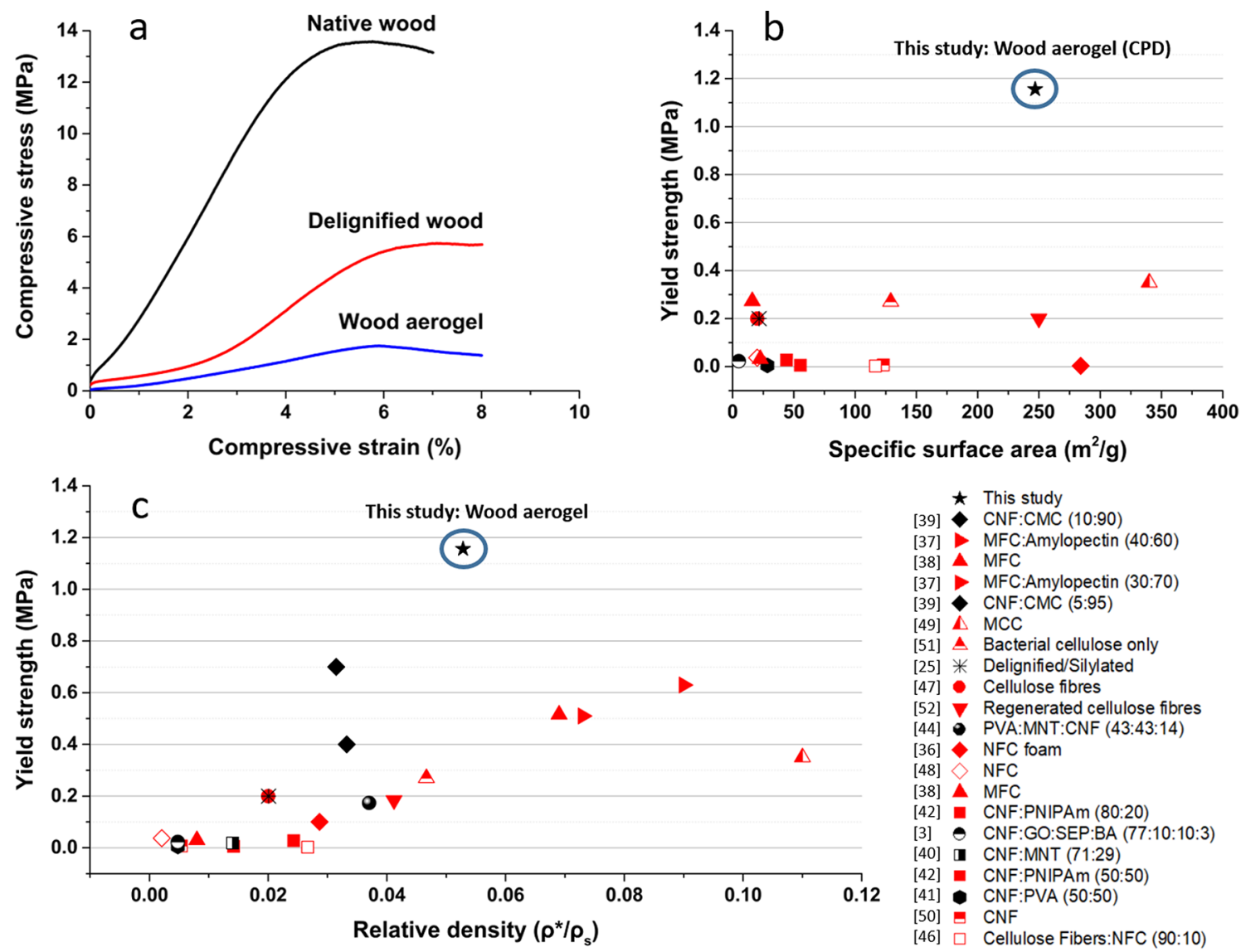

Figure 5. (a) Compressive stress-strain curves of native wood, delignified wood, and wood aerogel, at $50 \%$ relative humidity and $23{ }^{\circ} \mathrm{C}$. $(\mathrm{b})$ Yield strength against the specific surface area for documented cellulose-based aerogels and foams. (c) Yield strength versus relative density

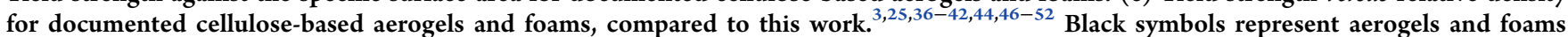
prepared to obtain anisotropy, whereas red symbols are aerogels and foams prepared with isotropic synthesis methods. $\rho^{*}$ represents the density of the individual porous material $\left(\mathrm{kg} / \mathrm{m}^{3}\right)$, and $\rho_{\mathrm{s}}$ represents the density of the solid cell wall material. Numbers in parentheses represent the wt \% of the component. Relative densities used were either retrieved from the article or calculated, where the solid density $1500 \mathrm{~kg} / \mathrm{m}^{3}$ was assumed for cellulose. ${ }^{34}$ 


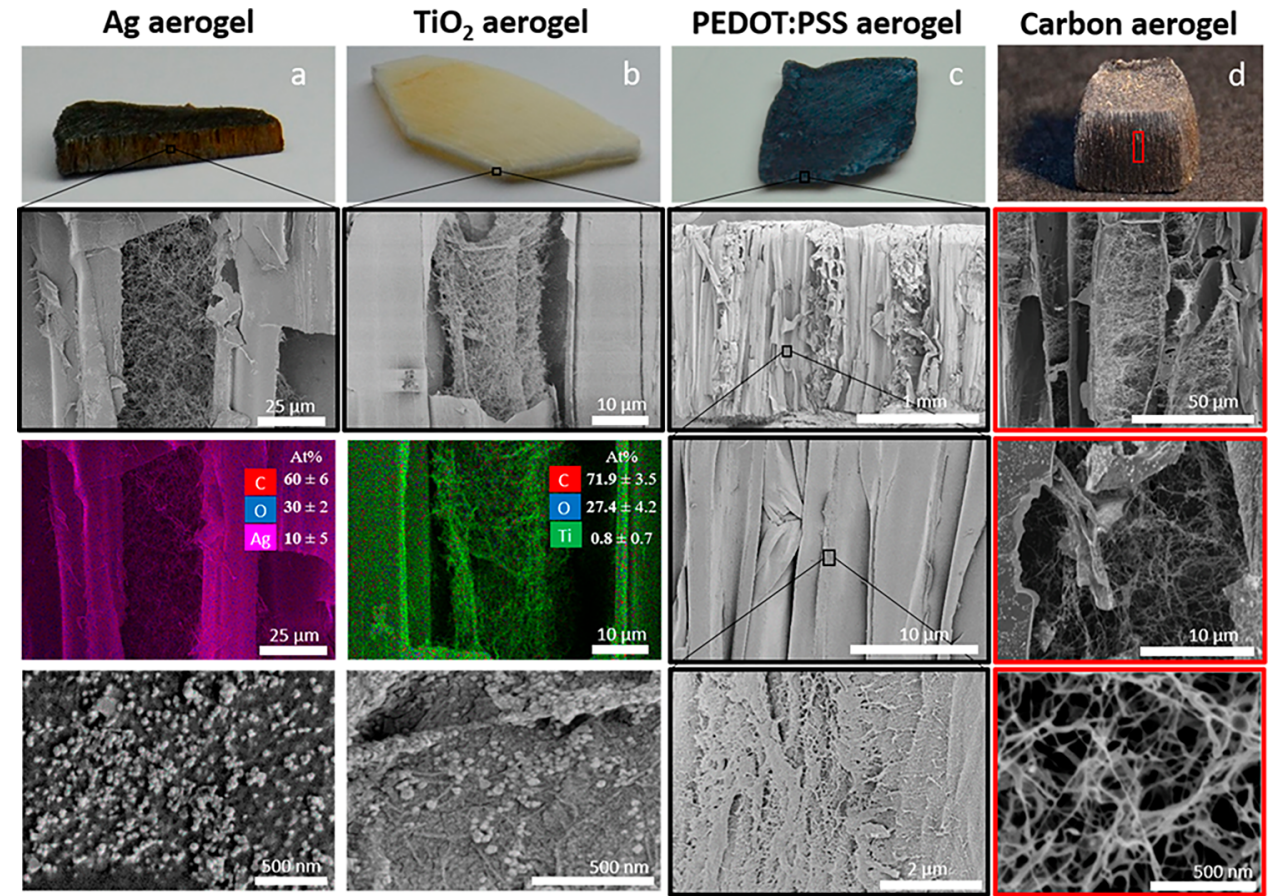

Figure 6. (a) Displaying an aerogel with reduced Ag particles. The SEM and EDX images show the fiber lumen where Ag particles are occurring in the fibrillated networks. (b) $\mathrm{TiO}_{2}$ aerogel followed by a SEM image portraying the particles deposited in the lumen as confirmed by EDX data. The elemental composition in the EDX images is in atomic \%. (c) PEDOT:PSS infiltrated aerogel and SEM images along the fiber direction. (d) Carbon aerogel followed by axial direction SEM images demonstrating the maintenance of partial fibrillation of the fiber cells.

is lowered compared with delignified wood. Mechanical properties from compression perpendicular to the longitudinal direction (radial direction) can be seen in Figure S4.

The wood aerogel is special in its combination of mechanical strength and high BET surface area, compared with cellulosebased aerogels and foams reported in the literature. ${ }^{3,25,35-52}$ Figure $5 b, c$ show the yield strength and BET surface area for documented cellulose-based aerogels and foams. In Figure 5c, the yield strength increases with higher relative density. The wood aerogel is positioned slightly higher than the anisotropic aerogel trend would suggest; see black symbols in Figure 5c.

A substantial advantage for the wood aerogel compared with anisotropic aerogels is the BET surface area of up to $247 \mathrm{~m}^{2} / \mathrm{g}$, compared with $20-30 \mathrm{~m}^{2} / \mathrm{g}^{25,41}$ for anisotropic nanocellulose aerogels, Figure $5 \mathrm{~b}$. The penalty in reduced strength for the wood aerogel is small. For isotropic aerogels, red symbols, a much lower yield strength at given relative density is observed. On the other hand, such aerogels can have BET surface areas of up to $340 \mathrm{~m}^{2} / \mathrm{g}$. ${ }^{49}$ Here, the preserved wood honeycomb structure and high microfibril orientation contribute to the strength, so that high strength and high specific surface area are combined.

The combination of high specific surface area and good mechanical properties is difficult to achieve; resolving that challenge for wood, a hierarchically structured template for multifunctional materials can be realized. The wood aerogel obtained in this work can be used to create nanostructured materials for high-technology applications. To demonstrate the possibility, four systems were used to functionalize the wood aerogel. They include in situ synthesis of metal nanoparticles (Ag) and metal oxide nanoparticles $\left(\mathrm{TiO}_{2}\right)$ and internal coating by conductive PEDOT:PSS polymer in the wood aerogel structure, followed by carbonization. Reduction of $\mathrm{Ag}$ from aqueous metal salts resulted in nanoparticle formation (Figure 6a) throughout the aerogels. The nanoparticles are present in both the fiber cell walls and the nanofiber networks in the lumen pore space; see SEM and energy-dispersive X-ray spectroscopy (EDX) images in Figure 6a. The $\mathrm{TiO}_{2}$ nanoparticles were also successfully precipitated inside the wood aerogel as confirmed by EDX data; see Figure $6 \mathrm{~b}$.

$\mathrm{Ag}$ aerogels have been investigated as functional materials for solar steam generation ${ }^{53}$ and antibacterial applications, ${ }^{54}$ and $\mathrm{TiO}_{2}$ aerogels have been studied as photocatalytic templates. ${ }^{55}$ In addition to nanoparticle functionalization, the wood aerogel could also be functionalized by layers of conductive polymer coatings inside the structure. The electrically highly conductive polymer PEDOT:PSS is infiltrated into the cellulosic matrix and forms a layer on the fiber cell walls (Figure 6c). A cross-section along the fiber direction after PEDOT:PSS infiltration is presented in Figure S5. The image confirms that the polymer is distributed throughout the fibers of the aerogel.

As a final demonstration, the unmodified, highly porous anisotropic aerogel was carbonized to form porous carbon aerogels; see Figure $6 \mathrm{~d}$. The carbonized wood aerogel shows a BET surface area of $555 \pm 3 \mathrm{~m}^{2} / \mathrm{g}$, more than double that of carbonized native wood $\left(235 \pm 4 \mathrm{~m}^{2} / \mathrm{g}\right)$. BET surface area isotherms are presented in Figure S6. The carbonized aerogel retains the anisotropic morphology of the wood aerogel, but the fiber lumen pore channels show a significantly smaller diameter. The overall shrinkage of the carbon aerogel is illustrated in Figure S1d. Native balsa wood has a fiber lumen diameter of approximately $18 \mu \mathrm{m},{ }^{22}$ but after carbonization the lumen diameter is decreased and the nanofibril structures in the cell lumen are still present. The carbon aerogel shows promise as a self-supporting, nonadditive, binder-free electrode 
with potential in supercapacitor applications. Capacitance measurements from cyclic voltammetry can be seen in Figure S8, where the carbon aerogel exhibited $66 \mathrm{~F} / \mathrm{g}$ compared to 5 $\mathrm{F} / \mathrm{g}$ for native carbonized wood at a scan rate of $10 \mathrm{mV} / \mathrm{s}$. Supporting SEM images of the carbon aerogel can be seen in Figure S7. Both the PEDOT:PSS-infiltrated wood aerogel and the carbon aerogel show good electrical conductivity with values of 213.7 and $371 \pm 5 \mathrm{~S} / \mathrm{m}$, respectively. In all cases, the partial nanofibrillation of the cell wall is maintained.

\section{CONCLUSIONS}

A highly porous, anisotropic aerogel of exceptionally high specific surface area combined with good mechanical properties is reported. It has a distinctive nanostructure, where a cellulose nanofibril network occupies the porous lumen space of wood cells. It is prepared from native wood using a topdown synthesis approach. Lignin is removed from the native wood cell wall to form a porous cellulose template for facile permeation of a cellulose solvent. The cosolvent partially dissolves the cell walls, with cellulose precipitation in the form of nanofibril networks inside the lumen. The aerogel exhibits a crystallinity index of $63 \%$, and the degree of crystalline cellulose I orientation is 0.84 .

The increased porosity and partial cell wall fibrillation results in specific surface areas as high as $247 \mathrm{~m}^{2} / \mathrm{g}$ for critical point drying and $159 \mathrm{~m}^{2} / \mathrm{g}$ for freeze-drying. The oriented honeycomb structure and high fibril orientation result in a yield strength of $1.2 \mathrm{MPa}$, at a porosity of $95 \%$. This is higher than for comparable isotropically structured nanocellulose aerogels.

The multifunctionality of the wood aerogel is demonstrated by three concepts: (a) through reduction of $\mathrm{Ag}$ and $\mathrm{TiO}_{2}$ for nanoparticle formation in the wood cell wall, (b) infiltration of the PEDOT:PSS conducting polymer, and (c) wood aerogel carbonization. Reduced nanoparticles form inside the oriented nanofibril cell wall as well as in the fibril networks inside the 20 $\mu \mathrm{m}$ lumen pore space of the aerogel. The electrically conductive PEDOT:PSS was readily impregnating the aerogel, and the carbonized aerogel also showed anisotropic character; both materials showed enhanced electrical conductivity. The present synthesis approach is a facile method to prepare anisotropic aerogels from wood of potential for multifunctional materials for applications such as sensors, chemical reactors, and electrical devices.

\section{EXPERIMENTAL SECTION}

Materials and Chemicals. Balsa wood (Ochroma pyramidale) with a density of $129 \pm 2 \mathrm{~kg} / \mathrm{m}^{3}$ was bought from Material $\mathrm{AB}$, Sweden, and subsequently cut to the dimensions of $15 \times 15 \times 10$ $\mathrm{mm}^{3}$ (tangential $\times$ radial $\times$ axial). The delignification chemical, sodium chlorite $\left(\mathrm{NaClO}_{2}\right)$, was purchased from Sigma-Aldrich, and the delignification buffer was prepared from sodium acetate and acetic acid, bought from Sigma-Aldrich, Sweden. The solvent exchange chemicals ethanol and acetone were purchased from VWR, Sweden. Lithium chloride $(\mathrm{LiCl})$ and dimethylacetamid (DMAc) for wood treatment was bought from Sigma-Aldrich, Sweden. Titanium(IV) butoxide (97\%), $\mathrm{AgNO}_{3}$ (>99\%), polyvinylpyrrolidone (molecular weight 10k), benzyl alcohol, and PEDOT:PSS (1.3 wt \%, conductive grade) were also purchased from Sigma-Aldrich, Sweden.

Delignification of Balsa Wood. This was performed by immersing the native wood into a solution containing $1 \mathrm{wt} \%$ sodium chlorite in an acetate buffer of $\mathrm{pH}$ 4.6. The delignification occurred for a duration of $18 \mathrm{~h}$, in which the buffer solution was renewed every
$6 \mathrm{~h}$. After delignification, the balsa templates were thoroughly rinsed with Milli-Q water.

Preparation of DMAc/LiCl-Treated Aerogels. Washed and delignified templates were introduced to an ethanol solvent exchange, followed by a DMAc solvent exchange. Solvent exchange was repeated four times, respectively. When the templates were completely infiltrated with DMAc, the samples were submerged in the DMAc/ $\mathrm{LiCl}$ solvent containing $8 \mathrm{wt} \% \mathrm{LiCl}$. The templates were treated for $24 \mathrm{~h}$ and subsequently introduced to a regeneration bath of acetone. The resultant templates were rinsed in Milli- $Q$ water and rapidly frozen in liquid nitrogen $\left(-196{ }^{\circ} \mathrm{C}\right)$, followed by freeze-drying $(-83$ ${ }^{\circ} \mathrm{C}$ ) for at least $48 \mathrm{~h}$ to yield aerogels. Aerogels were also obtained from critical point drying, in which the templates were first solvent exchanged to ethanol followed by CPD in an Autosamdri-815.

In Situ Synthesis of Nanoparticles (NPs) in the Aerogel. This was performed with a temperature-controlled microwave oven (Biotage Initiator). Time and temperature was adjusted according to the specimen and was subsequently cooled with compressed air to $50{ }^{\circ} \mathrm{C}$ after completion. Silver NPs were synthesized by mixing a solution of $2 \mathrm{~mL}$ of $25 \mathrm{mM}$ 10k polyvinylpyrrolidone and $2 \mathrm{~mL}$ of 25 $\mathrm{mM} \mathrm{AgNO}$. The aerogels were immersed into the mixture under vacuum for at least $4 \mathrm{~h}$. The $\mathrm{Ag}$ reduction was executed at a temperature of $120{ }^{\circ} \mathrm{C}$ for $10 \mathrm{~min}$ in the microwave. For the titania synthesis, the aerogel was solvent exchanged from water to benzyl alcohol for $12 \mathrm{~h}$, to ensure complete infiltration. A $14 \mu \mathrm{L}(0.04 \mathrm{mmol})$ amount of titanium butoxide was mixed into $4 \mathrm{~mL}$ of benzyl alcohol, and the aerogel was then submerged into the mixture. The heating was then performed in two consecutive steps. First, the mixture was heated to $50{ }^{\circ} \mathrm{C}$ for $5 \mathrm{~min}$ followed by $120{ }^{\circ} \mathrm{C}$ for $10 \mathrm{~min}$. The samples were thereafter cleaned in acetone for 20 min under vacuum; this was repeated four times. Lastly, the samples were solvent exchanged for water and freeze-dried for $24 \mathrm{~h}$. Ag and $\mathrm{TiO}_{2}$ was reduced on the cellulose template following a similar approach detailed by Roig et al. ${ }^{56}$ The proposed reaction mechanism can be seen elsewhere. ${ }^{56-58}$

Wood Carbonization. Native wood and freeze-dried DMAc/ LiCl-treated delignified wood was pyrolyzed in a tubular furnace (model: Nabertherm, tube furnace R 50/250/13). The pyrolysis transpired in a $\mathrm{N}_{2}$ atmosphere $(100 \mathrm{~mL} / \mathrm{min}$ flow $)$ with a heating rate of $5{ }^{\circ} \mathrm{C} / \mathrm{min}$ from RT to $1000{ }^{\circ} \mathrm{C}$, in which an isothermal treatment occurred for $3 \mathrm{~h}$ in a nitrogen atmosphere. Thereafter, the samples were cooled at a rate of $10^{\circ} \mathrm{C} / \mathrm{min}$.

PEDOT:PSS Aerogel Preparation. Aerogels were infiltrated with the conductive polymer PEDOT:PSS by filtrating a $1.3 \mathrm{wt} \%$ PEDOT:PSS solution dropwise onto the aerogel, using a Büchner funnel. The PEDOT:PSS retentate during filtration was reintroduced to the aerogel three consecutive times to ensure complete infiltration of the polymer. The infiltrated aerogels were thereafter washed in water and subsequently freeze-dried to obtain the conductive aerogels.

Characterization. Morphology of native wood, delignified wood, and the wood aerogel was analyzed using a field emission scanning electron microscope (Hitachi S-4800, Japan). The samples were sputtered with a platinum/palladium conductive layer using a Cressington 208HR, UK, for $20 \mathrm{~s}$, resulting in a layer thickness of approximately $3 \mathrm{~nm}$. Positioned on the FE-SEM an EDX instrument (Oxford Instruments, X-MAX N 80, UK) was equipped. EDX was used to evaluate the presence of elements and was carried out with an accelerating voltage of $15 \mathrm{kV}$ during $\mathrm{TiO}_{2}$ sample examination and 30 $\mathrm{kV}$ for the Ag specimen. The working distance was $15 \mathrm{~mm}$, and the composition was gathered with a point ID analysis, taken from six different regions of the EDX images. The density of the specimens was obtained by drying the samples in a $105{ }^{\circ} \mathrm{C}$ oven overnight, followed $30 \mathrm{~min}$ under vacuum before weighing. Thereafter, the porosity was calculated by utilizing eq 1 , where the solid density of balsa wood was assigned as $1500 \mathrm{~kg} / \mathrm{m}^{3}$ and solid density of cellulose as $1500 \mathrm{~kg} / \mathrm{m}^{3}$. 34 


$$
f=1-\frac{\text { Density of specimen }\left[\frac{\mathrm{kg}}{\mathrm{m}^{3}}\right]}{\text { Solid wood density }\left[\frac{\mathrm{kg}}{\mathrm{m}^{3}}\right]}
$$

The mechanical strength was evaluated through longitudinal compression in a Instron 5966, utilizing a $10 \mathrm{kN}$ load cell at a strain rate of $10 \% / \mathrm{min}, 23{ }^{\circ} \mathrm{C}$, and a $50 \%$ relative humidity. All specimens had dimensions of $15 \times 15 \times 10 \mathrm{~mm}^{3}$ (tangential $\times$ radial $\times$ axial). The Young's modulus is evaluated by observing the slope of the initial linear region of the stress to strain curves. The yield point $\left(\sigma_{\mathrm{p}}\right)$ represents the stress at which a structural collapse transpires. At the yield point, a plastic deformation initiates and the material can no longer be recovered elastically. The yield strength is evaluated as the stress at the intersection between the tangent line of the elastic region and the tangent line of the plateau region. XRD was performed using a Thermo Fisher Scientific ARL X'TRA powder diffractometer through $\mathrm{Cu} \mathrm{K} \alpha$ radiation at $40 \mathrm{~mA}$ and $45 \mathrm{kV}$. The scans were performed over $2 \theta$ of $5-50^{\circ}$ with a step size of $0.04^{\circ}$. The crystallinity index was obtained from two methods, peak height and peak deconvolution. ${ }^{59}$ In the former (peak height method), the CI was obtained from the intensity ratio of the [200] crystalline peak $\left(I_{200}-\right.$ $\left.I_{\mathrm{am}}\right)$ and the total peak intensity $\left(I_{200}\right)$, according to eq 2 . In the latter (peak deconvolution), the crystalline peaks were individually fitted using a Gaussian function. The amorphous contribution was assigned to $\sim 21.5^{\circ}$, and iterations were performed until reaching an $R^{2}$ value of 0.99 .

$$
\mathrm{CI}=\frac{I_{200}-I_{\text {Amorphous }}}{I_{200}}
$$

Two-dimensional WAXS was performed with a single-crystal X-ray diffractometer (Bruker D8 Venture, USA). The diffraction patterns were recorded by mounting thin slices of the samples, cut along the transversal direction. The samples were positioned perpendicularly to the incident beam to obtain two-dimensional diffraction patterns. The orientation of fibrils was achieved by azimuthal integration along the Debye-Scherrer ring of crystalline cellulose (200). Gaussian fit was performed on the obtained intensity profiles to obtain the full width at half-maximum (fwhm). The degree of orientation was calculated from the obtained fwhm according to eq 3 , where $f=1$ refers to a perfect orientation and $f=0$ represents an entirely random orientation.

$$
f=\frac{180-\text { fwhm }}{180}
$$

Carbohydrate analysis was performed by grinding the specimen in a Wiley mill, followed by complete hydrolysis of the ground material. The carbohydrate analysis was subsequently performed by introducing the hydrolyzed substance to a Dionex ICS-3000 ion chromatography system (Thermo Fisher Scientific Inc., USA). The lignin content was evaluated with the TAPPI T 222 om-2 method (Klason lignin). The BET specific surface area was evaluated by nitrogen physisorption. ${ }^{60}$ Prior to the nitrogen adsorption, $0.1 \mathrm{~g}$ of material was degassed at $90{ }^{\circ} \mathrm{C}$ for 2 days, followed by the subsequent BET analysis. The analysis was carried out at $-196{ }^{\circ} \mathrm{C}$ under a relative vapor pressure of $0.05-0.25$ with a Micromeritics ASAP 2020. The BET specific surface area was calculated from the attained isotherms. Finally, electrical conductivity was measured using an Ossila fourpoint probe system.

\section{ASSOCIATED CONTENT}

\section{SI Supporting Information}

The Supporting Information is available free of charge at https://pubs.acs.org/doi/10.1021/acsnano.0c01888.

Digital images representing dimensional changes of the material throughout the preparation procedure; data of dimensional changes, weight, and density during the preparation procedure; diameter distribution of regenerated fibrils; SEM images of nanofibrillated networks inside the aerogel; compressive stress-strain curves in the radial direction of specimens; digital image of the PEDOT:PSS-infiltrated aerogel; adsorption and desorption isotherms of carbonized wood and carbonized wood aerogel; SEM images showing the maintained nanofibrillated networks inside the carbonized aerogel; specific capacitance from cyclic voltammetry of the carbon aerogel and native carbonized wood (PDF)

\section{AUTHOR INFORMATION}

\section{Corresponding Author}

Yuanyuan Li - Wallenberg Wood Science Center, Department of Fiber and Polymer Technology, KTH Royal Institute of Technology, SE-10044 Stockholm, Sweden; 이이. orcid.org/00000002-1591-5815; Email: yua@kth.se

\section{Authors}

Jonas Garemark - Wallenberg Wood Science Center, Department of Fiber and Polymer Technology, KTH Royal Institute of Technology, SE-10044 Stockholm, Sweden

Xuan Yang - Wallenberg Wood Science Center, Department of Fiber and Polymer Technology, KTH Royal Institute of Technology, SE-10044 Stockholm, Sweden; 이이이.org/00000002-1336-5119

Xia Sheng - Department of Chemistry, School of Engineering Sciences in Chemistry, Biotechnology and Health, KTH Royal Institute of Technology, 10044 Stockholm, Sweden

Ocean Cheung - Department of Engineering Sciences, Nanotechnology and Functional Materials, Uppsala University, 75121 Uppsala, Sweden; 이이.org/0000-0002-4072-4324

Licheng Sun - Department of Chemistry, School of Engineering Sciences in Chemistry, Biotechnology and Health, KTH Royal Institute of Technology, 10044 Stockholm, Sweden; (i) orcid.org/0000-0002-4521-2870

Lars A. Berglund - Wallenberg Wood Science Center, Department of Fiber and Polymer Technology, KTH Royal Institute of Technology, SE-10044 Stockholm, Sweden; (1) orcid.org/0000-0001-5818-2378

Complete contact information is available at:

https://pubs.acs.org/10.1021/acsnano.0c01888

\section{Notes}

The authors declare no competing financial interest.

\section{ACKNOWLEDGMENTS}

The authors acknowledge the Knut \& Alice Foundation through the Wallenberg Wood Science Center. Y.Y.L. acknowledges the funding from Vetenskapsrådet (VR, No. 2017-05349), the fundings from KTH (SJTU-KTH collaborative research and development seed grant) and $\mathrm{KTH}$ energy platform. L.A.B. acknowledges European Research Council funding for Advanced Grant WoodNanoTech (No. 742733). We particularly thank Pernilla Karlsson for sharing valuable knowledge about $\mathrm{DMAc} / \mathrm{LiCl}$ cellulose dissolution mechanisms.

\section{REFERENCES}

(1) McNaught, A. D.; Wilkinson, A. IUPAC. Compendium of Chemical Terminology ("Gold Book"), 2nd ed.; Blackwell Scientific Publications: Oxford, 1997; pp 1-1622.

(2) Biener, J.; Stadermann, M.; Suss, M.; Worsley, M. A.; Biener, M. M.; Rose, K. A.; Baumann, T. F. Advanced Carbon Aerogels for Energy Applications. Energy Environ. Sci. 2011, 4, 656-667. 
(3) Wicklein, B.; Kocjan, A.; Salazar-Alvarez, G.; Carosio, F.; Camino, G.; Antonietti, M.; Bergström, L. Thermally Insulating and Fire-Retardant Lightweight Anisotropic Foams Based on Nanocellulose and Graphene Oxide. Nat. Nanotechnol. 2015, 10, 277-283.

(4) Liebner, F.; Haimer, E.; Wendland, M.; Neouze, M. A.; Schlufter, K.; Miethe, P.; Heinze, T.; Potthast, A.; Rosenau, T. Aerogels from Unaltered Bacterial Cellulose: Application of $\mathrm{scCO}_{2}$ Drying for the Preparation of Shaped, Ultra-Lightweight Cellulosic Aerogels. Macromol. Biosci. 2010, 10, 349-352.

(5) Ganesan, K.; Budtova, T.; Ratke, L.; Gurikov, P.; Baudron, V.; Preibisch, I.; Niemeyer, P.; Smirnova, I.; Milow, B. Review on the Production of Polysaccharide Aerogel Particles. Materials 2018, 11, 2144.

(6) Mehling, T.; Smirnova, I.; Guenther, U.; Neubert, R. H. H. Polysaccharide-Based Aerogels as Drug Carriers. J. Non-Cryst. Solids 2009, 355, 2472-2479.

(7) Chang, X.; Chen, D.; Jiap, X. Chitosan-Based Aerogels with High Adsorption Performance. J. Phys. Chem. B 2008, 112, 7721-7725.

(8) De France, K.; Hoare, T.; Cranston, E. Review of Hydrogels and Aerogels Containing Nanocellulose. Chem. Mater. 2017, 29, 46094631.

(9) Song, J.; Chen, C.; Yang, Z.; Kuang, Y.; Li, T.; Li, Y.; Huang, H.; Kierzewski, I.; Liu, B.; He, S.; Gao, T.; Yuruker, S. U.; Gong, A.; Yang, B.; Hu, L. Highly Compressible, Anisotropic Aerogel with Aligned Cellulose Nanofibers. ACS Nano 2018, 12, 140-147.

(10) Kriechbaum, K.; Munier, P.; Apostolopoulou-Kalkavoura, V.; Lavoine, N. Analysis of the Porous Architecture and Properties of Anisotropic Nanocellulose Foams: A Novel Approach to Assess the Quality of Cellulose Nanofibrils (CNFs). ACS Sustainable Chem. Eng. 2018, 6, 11959-11967.

(11) García-González, C. A.; Alnaief, M.; Smirnova, I. Polysaccharide-Based Aerogels-Promising Biodegradable Carriers for Drug Delivery Systems. Carbohydr. Polym. 2011, 86, 1425-1438.

(12) Jiang, F.; Hsieh, Y. L. Super Water Absorbing and Shape Memory Nanocellulose Aerogels from TEMPO-Oxidized Cellulose Nanofibrils via Cyclic Freezing-Thawing. J. Mater. Chem. A 2014, 2, 350-359.

(13) Guan, L. Z.; Gutiérrez, M. C.; Roldán-Ruiz, M. J.; Jiménez, R.; Ferrer, M. L.; del Monte, F. Highly Efficient and Recyclable CarbonNanofiber-Based Aerogels for Ionic Liquid-Water Separation and Ionic Liquid Dehydration in Flow-Through Conditions. Adv. Mater. 2019, 31, 1903418.

(14) Zu, G.; Shen, J.; Zou, L.; Wang, F.; Wang, X.; Zhang, Y.; Yao, $X$. Nanocellulose-Derived Highly Porous Carbon Aerogels for Supercapacitors. Carbon 2016, 99, 203-211.

(15) Saito, T.; Kimura, S.; Nishiyama, Y.; Isogai, A. Cellulose Nanofibers Prepared by TEMPO-Mediated Oxidation of Native Cellulose. Biomacromolecules 2007, 8, 2485-2491.

(16) Pääkkö, M.; Ankerfors, M.; Kosonen, H.; Nykänen, A.; Ahola, S.; Österberg, M.; Ruokolainen, J.; Laine, J.; Larsson, P. T.; Ikkala, O.; Lindström, T. Enzymatic Hydrolysis Combined with Mechanical Shearing and High-Pressure Homogenization for Nanoscale Cellulose Fibrils and Strong Gels. Biomacromolecules 2007, 8, 1934-1941.

(17) Sacui, I. A.; Nieuwendaal, R. C.; Burnett, D. J.; Stranick, S. J.; Jorfi, M.; Weder, C.; Foster, E. J.; Olsson, R. T.; Gilman, J. W. Comparison of the Properties of Cellulose Nanocrystals and Cellulose Nanofibrils Isolated from Bacteria, Tunicate, and Wood Processed Using Acid, Enzymatic, Mechanical, and Oxidative Methods. ACS Appl. Mater. Interfaces 2014, 6, 6127-6138.

(18) Thorkelsson, K.; Bai, P.; Xu, T. Self-Assembly and Applications of Anisotropic Nanomaterials: A Review. Nano Today 2015, 10, 4866.

(19) Kuang, Y.; Chen, C.; He, S.; Hitz, E. M.; Wang, Y.; Gan, W.; Mi, R.; Hu, L. A High-Performance Self-Regenerating Solar Evaporator for Continuous Water Desalination. Adv. Mater. 2019, 31, 1900498.

(20) Munier, P.; Gordeyeva, K.; Bergström, L.; Fall, A. B. Directional Freezing of Nanocellulose Dispersions Aligns the Rod-Like Particles and Produces Low-Density and Robust Particle Networks. Biomacromolecules 2016, 17, 1875-1881.

(21) Zhang, X.; Yu, Y.; Jiang, Z.; Wang, H. The Effect of Freezing Speed and Hydrogel Concentration on the Microstructure and Compressive Performance of Bamboo-Based Cellulose Aerogel. J. Wood Sci. 2015, 61, 595-601.

(22) Borrega, M.; Ahvenainen, P.; Serimaa, R.; Gibson, L. Composition and Structure of Balsa (Ochroma Pyramidale) Wood. Wood Sci. Technol. 2015, 49, 403-420.

(23) Burgert, I.; Cabane, E.; Zollfrank, C.; Berglund, L. Bio-Inspired Functional Wood-Based Materials - Hybrids and Replicates. Int. Mater. Rev. 2015, 60, 431-450.

(24) Zhu, H.; Luo, W.; Ciesielski, P. N.; Fang, Z.; Zhu, J. Y.; Henriksson, G.; Himmel, M. E.; Hu, L. Wood-Derived Materials for Green Electronics, Biological Devices, and Energy Applications. Chem. Rev. 2016, 116, 9305-9374.

(25) Guan, H.; Cheng, Z.; Wang, X. Highly Compressible Wood Sponges with A Spring-Like Lamellar Structure as Effective and Reusable Oil Absorbents. ACS Nano 2018, 12, 10365-10373.

(26) Frey, M.; Widner, D.; Segmehl, J. S.; Casdorff, K.; Keplinger, T.; Burgert, I. Delignified and Densified Cellulose Bulk Materials with Excellent Tensile Properties for Sustainable Engineering. ACS Appl. Mater. Interfaces 2018, 10, 5030-5037.

(27) Fu, Q.; Ansari, F.; Zhou, Q.; Berglund, L. A. Wood Nanotechnology for Strong, Mesoporous, and Hydrophobic Biocomposites for Selective Separation of Oil/Water Mixtures. ACS Nano 2018, 12, 2222-2230.

(28) McCormick, C. L.; Callais, P. A.; Hutchinson, B. H. Solution Studies of Cellulose in Lithium Chloride and N, N-Dimethylacetamide. Macromolecules 1985, 18, 2394-2401.

(29) Dawsey, T. R.; Mccormick, C. L. The Lithium Chloride/ Dimethylacetamide Solvent for Cellulose - A Literature-Review. J. Macromol. Sci., Polym. Rev. 1990, C30, 405-440.

(30) Zhang, C.; Liu, R.; Xiang, J.; Kang, H.; Liu, Z.; Huang, Y. Dissolution Mechanism of Cellulose in N, N-Dimethylacetamide/ Lithium Chloride: Revisiting through Molecular Interactions. J. Phys. Chem. B 2014, 118, 9507-9514.

(31) Jin, H.; Nishiyama, Y.; Wada, M.; Kuga, S. Nanofibrillar Cellulose Aerogels. Colloids Surf., A 2004, 240, 63-67.

(32) Duchemin, B.; Newman, R.; Staiger, M. Phase Transformations in Microcrystalline Cellulose Due to Partial Dissolution. Cellulose 2007, 14, 311-320.

(33) Abe, K.; Yamamoto, H. Mechanical Interaction between Cellulose Microfibril and Matrix Substance in Wood Cell Wall Determined by X-Ray Diffraction. J. Wood Sci. 2005, 51, 334-338.

(34) Gibson, L. J.; Ashby, M. F. The Structure of Cellular Solids. Cellular Solids: Structure and Properties, 2nd ed.; Cambridge University Press: Cambridge, 1997; pp 15-51.

(35) Zhang, R.; Chen, Q.; Zhen, Z.; Jiang, X.; Zhong, M.; Zhu, H. Cellulose-Templated Graphene Monoliths with Anisotropic Mechanical, Thermal, and Electrical Properties. ACS Appl. Mater. Interfaces 2015, 7, 19145-19152.

(36) Sehaqui, H.; Zhou, Q.; Berglund, L. A. High-Porosity Aerogels of High Specific Surface Area Prepared from Nanofibrillated Cellulose (NFC). Compos. Sci. Technol. 2011, 71, 1593-1599.

(37) Svagan, A. J.; Samir, M. A. S. A.; Berglund, L. A. Biomimetic Foams of High Mechanical Performance Based on Nanostructured Cell Walls Reinforced by Native Cellulose Nanofibrils. Adv. Mater. 2008, 20, 1263-1269.

(38) Sehaqui, H.; Salajková, M.; Zhou, Q.; Berglund, L. A. Mechanical Performance Tailoring of Tough Ultra-High Porosity Foams Prepared from Cellulose I Nanofiber Suspensions. Soft Matter 2010, 6, 1824-1832.

(39) Chen, B.; Zheng, Q.; Zhu, J.; Li, J.; Cai, Z.; Chen, L.; Gong, S. Mechanically Strong Fully Biobased Anisotropic Cellulose Aerogels. RSC Adv. 2016, 6, 96518-96526.

(40) Donius, A. E.; Liu, A.; Berglund, L. A.; Wegst, U. G. K. Superior Mechanical Performance of Highly Porous, Anisotropic Nano- 
cellulose-Montmorillonite Aerogels Prepared by Freeze Casting. J. Mech. Behav. Biomed. Mater. 2014, 37, 88-99.

(41) Zhang, X.; Wang, H.; Cai, Z.; Yan, N.; Liu, M.; Yu, Y. Highly Compressible and Hydrophobic Anisotropic Aerogels for Selective Oil/Organic Solvent Absorption. ACS Sustainable Chem. Eng. 2019, 7, 332-340.

(42) Zhang, X.; Wang, Y.; Zhao, J.; Xiao, M.; Zhang, W.; Lu, C. Mechanically Strong and Thermally Responsive Cellulose Nanofibers/Poly(N-Isopropylacrylamide) Composite Aerogels. ACS Sustainable Chem. Eng. 2016, 4, 4321-4327.

(43) Cervin, N. T.; Johansson, E.; Larsson, P. A.; Wågberg, L. Strong, Water-Durable, and Wet-Resilient Cellulose NanofibrilStabilized Foams from Oven Drying. ACS Appl. Mater. Interfaces 2016, 8, 11682-11689.

(44) Liu, A.; Medina, L.; Berglund, L. A. High-Strength Nanocomposite Aerogels of Ternary Composition: Poly(vinyl Alcohol), Clay, and Cellulose Nanofibrils. ACS Appl. Mater. Interfaces 2017, 9, 6453-6461.

(45) Svagan, A. J.; Berglund, L. A.; Jensen, P. Cellulose Nanocomposite Biopolymer Foam-Hierarchical Structure Effects on Energy Absorption. ACS Appl. Mater. Interfaces 2011, 3, 14111417.

(46) Seantier, B.; Bendahou, D.; Bendahou, A.; Grohens, Y.; Kaddami, H. Multi-Scale Cellulose Based New Bio-Aerogel Composites with Thermal Super-Insulating and Tunable Mechanical Properties. Carbohydr. Polym. 2016, 138, 335-348.

(47) Pääkkö, M.; Vapaavuori, J.; Silvennoinen, R.; Kosonen, H.; Ankerfors, M.; Lindström, T.; Berglund, L. A.; Ikkala, O. Long and Entangled Native Cellulose I Nanofibers Allow Flexible Aerogels and Hierarchically Porous Templates for Functionalities. Soft Matter 2008, 4, 2492-2499.

(48) Xiao, S.; Gao, R.; Lu, Y.; Li, J.; Sun, Q. Fabrication and Characterization of Nanofibrillated Cellulose and Its Aerogels from Natural Pine Needles. Carbohydr. Polym. 2015, 119, 202-209.

(49) Schestakow, M.; Karadagli, I.; Ratke, L. Cellulose Aerogels Prepared from an Aqueous Zinc Chloride Salt Hydrate Melt. Carbohydr. Polym. 2016, 137, 642-649.

(50) Jiang, F.; Hsieh, Y. L. Cellulose Nanofibril Aerogels: Synergistic Improvement of Hydrophobicity, Strength, and Thermal Stability via Cross-Linking with Diisocyanate. ACS Appl. Mater. Interfaces 2017, 9, $2825-2834$.

(51) Sai, H.; Xing, L.; Xiang, J.; Cui, L.; Jiao, J.; Zhao, C.; Li, Z.; Li, F.; Zhang, T. Flexible Aerogels with Interpenetrating Network Structure of Bacterial Cellulose-Silica Composite from Sodium Silicate Precursor via Freeze Drying Process. RSC Adv. 2014, 4, 30453-30461.

(52) Pircher, N.; Carbajal, L.; Schimper, C.; Bacher, M.; Rennhofer, H.; Nedelec, J.-M.; Lichtenegger, H. C.; Rosenau, T.; Liebner, F. Impact of Selected Solvent Systems on the Pore and Solid Structure of Cellulose Aerogels. Cellulose 2016, 23, 1949-1966.

(53) Zhu, M.; Li, Y.; Chen, F.; Zhu, X.; Dai, J.; Li, Y.; Yang, Z.; Yan, X.; Song, J.; Wang, Y.; Hitz, E.; Luo, W.; Lu, M.; Yang, B.; Hu, L. Plasmonic Wood for High-Efficiency Solar Steam Generation. Adv. Energy Mater. 2018, 8, 1701028.

(54) Matsuyama, K.; Morotomi, K.; Inoue, S.; Nakashima, M.; Nakashima, H.; Okuyama, T.; Kato, T.; Muto, H.; Sugiyama, H. Antibacterial and Antifungal Properties of Ag Nanoparticle-Loaded Cellulose Nanofiber Aerogels Prepared by Supercritical $\mathrm{CO}_{2}$ Drying. J. Supercrit. Fluids 2019, 143, 1-7.

(55) Dal'Acqua, N.; Mattos, A. B. d.; Krindges, I.; Pereira, M. B.; Barud, H. d. S.; Ribeiro, S. J. L.; Duarte, G. C. S.; Radtke, C.; Almeida, L. C.; Giovanela, M.; Crespo, J. d. S.; Machado, G. Characterization and Application of Nanostructured Films Containing $\mathrm{Au}$ and $\mathrm{TiO}_{2}$ Nanoparticles Supported in Bacterial Cellulose. J. Phys. Chem. C 2015, $119,340-349$.

(56) Roig-Sanchez, S.; Jungstedt, E.; Anton-Sales, I.; Malaspina, D. C.; Faraudo, J.; Berglund, L. A.; Laromaine, A.; Roig, A. Nanocellulose Films with Multiple Functional Nanoparticles in Confined Spatial Distribution. Nanoscale Horiz. 2019, 4, 634-641.
(57) Hoppe, C. E.; Lazzari, M.; Pardiñas-Blanco, I.; López-Quintela, M. A. One-Step Synthesis of Gold and Silver Hydrosols Using Poly(N-Vinyl-2-Pyrrolidone) as a Reducing Agent. Langmuir 2006, 22, 7027-7034.

(58) Niederberger, M.; Bartl, M. H.; Stucky, G. D. Benzyl Alcohol and Titanium Tetrachloride - A Versatile Reaction System for the Nonaqueous and Low-Temperature Preparation of Crystalline and Luminescent Titania Nanoparticles. Chem. Mater. 2002, 14, 43644370.

(59) Park, S.; Baker, J. O.; Himmel, M. E.; Parilla, P. A.; Johnson, D. K. Cellulose Crystallinity Index: Measurement Techniques and Their Impact on Interpreting Cellulase Performance. Biotechnol. Biofuels 2010, 3, 1-10.

(60) Brunauer, S.; Emmett, P. H.; Teller, E. Adsorption of Gases in Multimolecular Layers. J. Am. Chem. Soc. 1938, 60, 309-319. 